\title{
Ileal Motility pattern In a Mouse Disease Model of Ulcerative Colitis
}

\author{
Suaad Al Mandhari ${ }^{1 *}$, Intisar Al Lawati ${ }^{2}$, Khalil Al Ajmi ${ }^{3}$, Adel Ahmidat ${ }^{4}$ and Ammar Boudaka \\ ${ }^{1}$ Intern, Department of Medicine, Sultan Qaboos University Hospital, Muscat, Oman \\ ${ }^{2}$ Biomedical Scientist, Department of Physiology, Sultan Qaboos University, Muscat, Oman
}

${ }^{3}$ Intern, Department of Surgery, Sultan Qaboos University, Muscat, Oman

${ }^{4}$ Consultant Obstetrician \&amp; Gynaecologist, York Teaching Hospital, United Kingdom

${ }^{5}$ Associate Professor, Department of Physiology, Sultan Qaboos University, Muscat, Oman

*Corresponding author: Suaad Al Mandhari, Intern, Department of Medicine, Sultan Qaboos University Hospital, Muscat, Oman

\section{ARTICLE INFO}

Received: 幽 December 23, 2020

Published: 幽 January 05, 2021

Citation: Suaad Al Mandhari, Ammar Boudaka, Khalil Al Ajmi, Adel Ahmidat. Ileal Motility pattern In a Mouse Disease Model of Ulcerative Colitis. Biomed J Sci \& Tech Res 32(5)-2021. BJSTR. MS.ID.005327.

Keywords: Ulcerative Colitis; Ileum; Motility; DSS

\section{ABSTRACT}

Background: Ulcerative colitis (UC), is an immune-mediated illness characterized by chronic intestinal inflammation. It is described as a multifactorial disease that involves both genetic and environmental components. UC might result in malabsorption, anemia, and colorectal cancers. There is no definitive treatment for ulcerative colitis, but treatment can help to suppress the inflammatory response and manage symptoms.

Objective: The aim of this research project is to study the ileal motility pattern in a disease model of ulcerative colitis in mice.

Methods: Ulcerative colitis was induced in mice following specific protocol by adding DSS substance in the drinking water of mice, then small strip of distal part of ileal tissue was cut and threaded to force transducer in pan lab setup which is connected to a computer screen to record muscle longitudinal activity. Acetylcholine and atropine were added and change in muscle activity was observed. Data was analyzed using Graph pad Prism Program ( $p$ value $<0.05$ was considered significant).

Results: The results showed regular and fast contractions with sharp peaks in both normal and DSS treated mice. It has been found that there is no significant difference in ileal contractions in both groups.

Conclusion: The overall findings showed that ulcerative colitis does not affect ileal motility as ileal tissue showed normal response to different chemicals that were added in the experiment.

\section{Introduction}

\section{Literature Review}

The small intestine is the longest part of the gastrointestinal tract and is about 20 feet long. The journey of food that passes from the stomach into the small intestine passes through three parts: first it enters the duodenum, then the jejunum, and finally the ileum. The ileum is the final section of the small intestine. The ileum follows the duodenum and jejunum and is separated from the cecum by the ileocecal valve. In humans, the ileum is about $2-4 \mathrm{~m}$ long, and the pH is usually between 7 and 8 (neutral or alkaline).
The function of the ileum is mainly to absorb vitamin $B_{12}$ and bile salts and whatever products of digestion that were not absorbed by the jejunum. The wall itself is made up of folds, each of which has many tiny finger-like projections known as villi on its surface. It has a large surface area for adsorption of digestion end products. Layers of circular and longitudinal smooth muscle enable the chyme, which is the digested food, to be pushed along the ileum by waves of muscle contractions called peristalsis. The remaining chyme is then passed to the colon. It is very important as it can be affected in a few diseases such as ulcerative colitis. 
Inflammatory bowel disease (IBD) encompasses a range of intestinal pathologies, the most common of which are ulcerative colitis (UC) and Crohn's Disease (CD). Both UC and CD, when present in the ileum, generate a similar symptom profile which can include diarrhea, rectal bleeding, abdominal pain, and weight loss.

Although the pathogenesis of IBD remains unknown, it is described as a multifactorial disease that involves both genetic and environmental components. UC might result in malabsorption, anemia, colorectal cancers and other complications outside the intestine. There is no specific diagnostic test for ulcerative colitis. However, some findings on biopsy and barium x-rays, as well as appearance during endoscopy give a clear diagnosis in most cases. Diagnosis of ulcerative colitis is based on medical history and physical examination, and the results of laboratory and endoscopic tests. There is no definitive treatment for ulcerative colitis, but treatment can help to suppress the inflammatory response and manage symptoms.

There are numerous and variable animal models of colonic inflammation that resemble several features of IBD. Animal models of colitis range from those arising spontaneously in susceptible strains of certain species to those requiring administration of specific concentrations of colitis-inducing chemicals, such as dextran sulphate sodium (DSS). Chemically induced models of gut inflammation are the most used and best described models of IBD [1]. An ideal experimental model of IBD should mimic human IBD, either ulcerative colitis or Crohn's disease (CD), quite closely. In addition, it should be simple to induce, not expensive and highly reproducible (Elson et al. 1995). Unfortunately, there is no single model available that meets these criteria. The dextran sulphate sodium (DSS) model of colitis is widely perceived as a good model of experimental colitis because it has similarities to human IBD in aetiology, pathology, pathogenesis and therapeutic response. In addition, induction is cheap and simple, and may be acute or chronic. (Elson et al. 1995). There has been suggestion that ulcerative colitis might affect the motility pattern of ileum which consequently leads to abnormal function. Therefore, the aim of this is experiment is to study the ileal motility pattern in a disease model of ulcerative colitis in mice. This model represents certain pathophysiological features of human's ulcerative colitis involving weight loss and diarrhea.

\section{Main Objective}

The aim of this project is to study the ileal motility pattern in a disease model of ulcerative colitis in mice.

\section{Specific Objectives}

a. To measure spontaneous ileal motility in normal and diseased mice.

b. To study the effects of different concentration of acetylcholine on ileal motility in normal and diseased mice.

\section{Materials and Methods}

\section{Animals and Tissue Preparation}

C57BL/6 male mice 8-9 weeks old were provided by Sultan Qaboos University Small Animal House. Mice were placed in a polypropylene cage under standard conditions (12h Light/ $12 \mathrm{~h}$ dark cycles, $22-24^{\circ} \mathrm{C}$ and about $50-60 \%$ humidity) with free access to water and food.

Mice were divided into two groups as follows:

a) 1-Control group (normal mice, free from UC), $(n=5)$

b) 2-Disease group (Abnormal mice, having UC), $(n=5)$.

UC was induced in mice by using dextran sodium sulphate (DSS), a negatively charged, water-soluble chemical. Mice in disease group were given $2.5 \%$ DSS with drinking water for five days. For the next five days, they were given free drinking water without DSS while control group were given tap water for the whole period of ten days. DSS was freshly prepared every other day. To ensure the induction of UC in mice, macroscopic examinations were done to determine disease activity index (DAI), which includes body weight, diarrhea, stool consistency and blood within stool. When UC was confirmed in the disease group, mice were killed under anesthesia following institutional animal ethical protocols. Ethical approval gained from college of medicine and health sciences ethics committee. After killing the mouse, ileum was isolated, placed in a petri dish containing ringer solution $(119 \mathrm{mM} \mathrm{NaCl}, 4.7 \mathrm{mM} \mathrm{KCl}$, $1.17 \mathrm{mM} \mathrm{MgSO}_{4}, 1.6 \mathrm{mM} \mathrm{CaCl}_{2}, 1.18 \mathrm{mM} \mathrm{KH}_{2} \mathrm{PO}_{4}, 25 \mathrm{mM} \mathrm{NaHCO}_{3}$ and $5.5 \mathrm{mM}$ glucose) at $\mathrm{pH}$ of 7.4 , at room temperature and saturated with $95 \% \mathrm{O}_{2} / 5 \% \mathrm{CO}_{2}$.

\section{Collection of Ileal Tissue}

A mixture of Ketamine $(140 \mathrm{mg} / \mathrm{kg}$ ) and Xylazine $(40 \mathrm{mg} /$ $\mathrm{kg}$ ) were injected in mice. Then, the abdomen was cut open in the midline and intestine was transected and transferred to cold oxygenated Ringer's solution. The distal part of the ileum was used to assess motility.

\section{Assessment of Ileal Damage Severity}

Macroscopic examinations were done to assess the degree of ileal damage, which included stool consistency and blood in the stool. Bleeding was checked using fecal blood occult test (FOBT). For this test, a small sample of mouse stool is placed on a special card containing guaiac resin as indicator. The developing reagent is a stabilized alcoholic solution of hydrogen peroxide, due to it is peroxidase like activity hemoglobin catalyzes the oxidation of the indicator by hydrogen peroxide causing the test paper to turn to blue in presence of blood (positive blood occult test). If no change in color occurs the test is considered negative. While stool consistency was assessed using a pair of forceps to press down on the feces to determine its consistency (Table 1). 
Table 1: Blood occult test scoring and stool consistency.

\begin{tabular}{|c|c|c|}
\hline Score & Stool & Blood occult test \\
\hline 0 & Normal & Negative $(-)$ \\
\hline 1 & Soft & Mild $(+)$ \\
\hline 2 & Very Soft & Moderate $(++)$ \\
\hline 3 & Diarrhea & Severe $(+++)$ \\
\hline
\end{tabular}

\section{Isometric Tension Recording}

The ileum was cleaned from surrounding adipose tissue and its fecal content by cold oxygenated Ringer solution. Then, the ileum was isolated and mounted in 10-ml organ bath containing cold Ringer solution ( $\mathrm{pH}=7.4$, temperature $37^{\circ} \mathrm{C}$ and bubbled with carbogen mixture $\left(95 \% \mathrm{O}_{2} / 5 \% \mathrm{CO}_{2}\right.$ gas). Resting tension of one gram was applied to each segment. One end of the ileal segment was fixed while the other one was threaded to a force transducer to record longitudinal muscle activity. Solution was changed every 30 minutes before staring the experiment, then the response of this longitudinal muscle activity was pharmacologically characterized in both groups using specific chemicals. Isometric response was filtered, amplified by an amplifier and recorded using Power Lab system Lab Chart ProV8 software (AD Instrument, Bella Vista NSW, Australia. At the beginning, ileal motility was assessed after adding acetylcholine in cumulative concentrations at 2-3 minutes intervals Table 2. The same protocol of ACh addition was repeated on tissues pre-incubated with atropine $(2 \mu \mathrm{l})$ for 20 minutes.

Table 2: Acetylcholine concentrations used for $10 \mathrm{ml}$ bath.

\begin{tabular}{|c|c|c|}
\hline \multirow{2}{*}{ Stock } & Dose & For $\mathbf{1 0 m l}$ bath $(\boldsymbol{\mu L})$ \\
\hline \multirow{3}{*}{$10 \mu \mathrm{M}$} & $1 \mathrm{~nm}$ & 1 \\
\cline { 2 - 3 } & $10 \mathrm{nM}$ & 9 \\
\cline { 2 - 3 } & $100 \mathrm{nM}$ & 90 \\
\hline \multirow{2}{*}{$1 \mathrm{mM}$} & $1 \mu \mathrm{m}$ & 9 \\
\cline { 2 - 3 } & $10 \mu \mathrm{M}$ & 90 \\
\hline
\end{tabular}

\section{Chemicals}

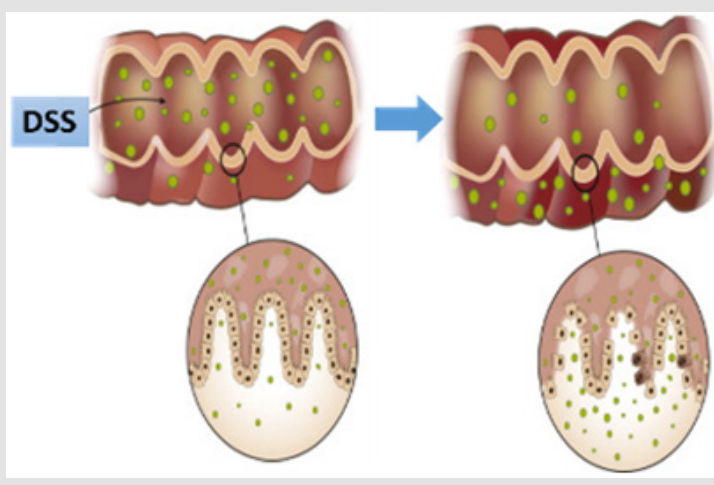

Figure 1: Mechanism of DSS inducing UC.

Dextran sulphate sodium (DSS, Uppsala, Sweden is a watersoluble, negatively charged sulfated polysaccharide with a highly variable molecular weight ranging from 5 to $1400 \mathrm{kDa}$. It causes colitis that resembles human UC (Okayasu et al., 1990). Mechanism of dextran sulfate sodium induced colitis is due to loss of epithelial barrier Figure 1 function and entry of luminal organisms or their products into the lamina propria. Such entry results in stimulation of innate and adaptive lymphoid elements and secretion of proinflammatory cytokines and chemokines. In addition, it results in the influx of cells with cytotoxic potential such as neutrophils and inflammatory macrophages.

\section{Other Chemicals:}

Ketamine hydrochloride, xylazine hydrochloride were purchased from Troy Laboratories (PTY. Limited, Australia). Acetylcholine chloride, atropine sulfate, sodium chloride, potassium chloride, potassium phosphate monobasic, magnesium sulfate, sodium bicarbonate and D- (+)-Glucose were obtained from Sigma (Germany). Calcium chloride solution and HEPES [4-(2-Hydroxyethyl) piperazine-1-ethanesulonic acid] were purchased from Fluka (Germany).

\section{Data Analysis}

Data were compared and analyzed using Microsoft Excel version (7) and Graph pad prism software (San Diego, CA, USA) version (6) using $t$-test and analysis of variance (ANOVA). Significance association between different groups, a $p$ value $<0.05$ was statistically significant.

\section{Results}

\section{Assessment of Ileal Damage Severity}

Macroscopic disease score was used to determine the severity of ulcerative colitis. Disease group showed stool consistency of different degrees some were soft, very soft and others watery stool. To determine a score for blood in stool, the color of the stool was noted and further validated using a FOBT and determine the degree using the scoring system Table 1. Most control mice showed score of zero which resembles normal stool and negative blood occult test while disease mice showed bloody soft stool with mild blood occult test (score 1), however some were negative blood occult test.

\section{Weight Change}

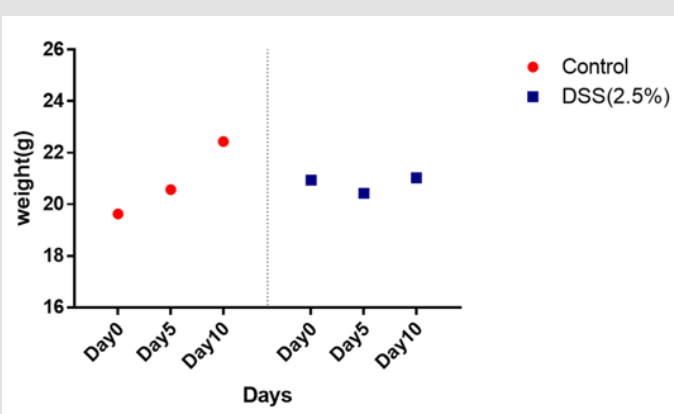

Figure 2: Weight change in disease and control group during period of treatment. Control group shows increase in weight throughout the induction period while disease group shows no significant weight change. 
Weights of mice were measured every day during the treatment period. Figure 2 shows weight changes in both control and disease groups. Weight increased in control group while it shows almost no weight change in the disease group. Spontaneous contractions observed in distal ileal preparations of wild-type mice could be evaluated based on frequency (either low or high frequency; event Count) Figure 3 and average cyclic height Figure 4. Typical spontaneous motility patterns with high-amplitude contractions (Pattern A), the control group while only small amplitude with high frequency (pattern B) the disease group, are shown in Figure 5.

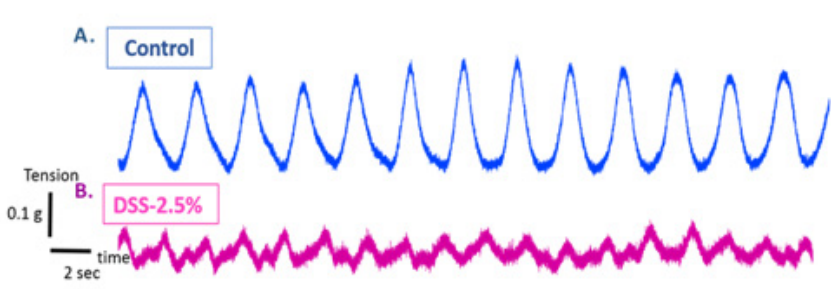

Figure 3: Typical spontaneous ileal motility contractions in control (A) and disease group (B) isolated from wild-type mice.

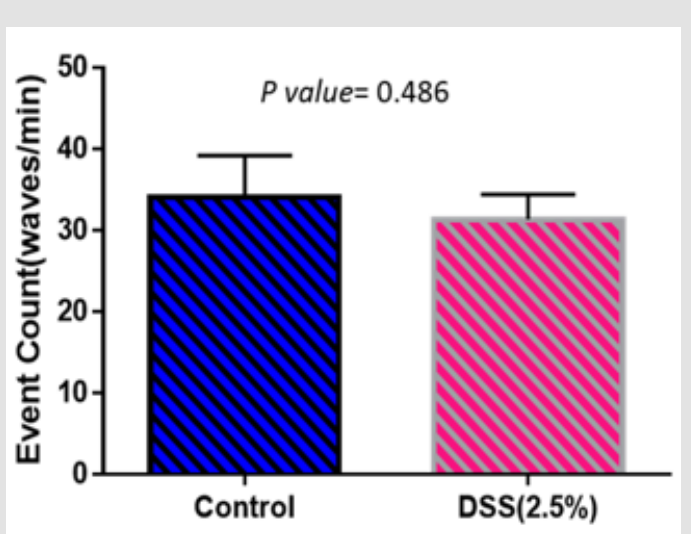

Figure 4: Event count in disease and control group. There is no significant difference in number of waves per minute in both groups.

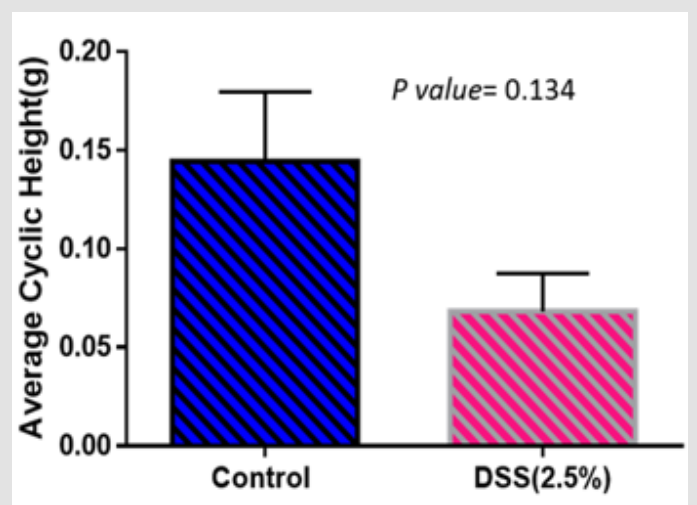

Figure 5: Average cyclic height in control group (amplitude) is higher in normal mice than the disease group.

\section{Response to Different Concentrations of $\mathrm{ACh}$ in the Presence and Absence of Atropine}

In the distal ileum of wild-type mice, acetylcholine caused concentration-dependent contractions (10nM-10 $\mu \mathrm{M})$ (Figure 6). Acetylcholine-induced contractions showed no significant difference in both groups. However, the contractions were slightly higher in the control group. Increasing acetylcholine concentrations in both groups result in increased ileal contractility amplitude These ACh-mediated contractions were inhibited by atropine $(2 \mu \mathrm{L})$ in both groups (Figure 7).

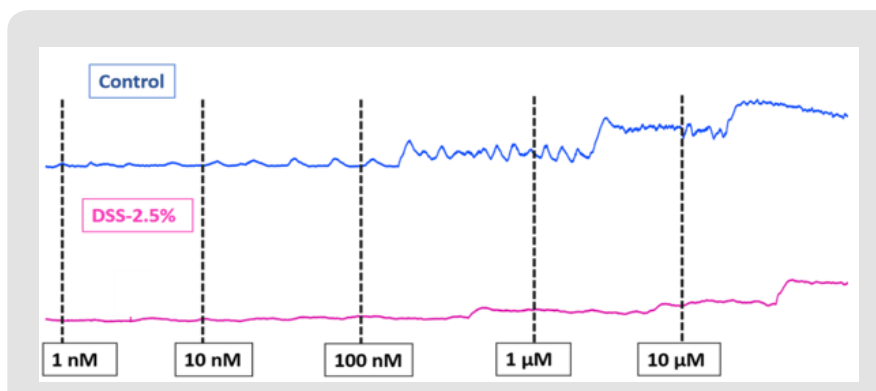

Figure 6: Ileal tissue response to different acetylcholine concentrations $(1 \mathrm{nM}-10 \mu \mathrm{M})$. Ileal tissue contractions increased in response to increasing acetylcholine concentrations in control and disease group.

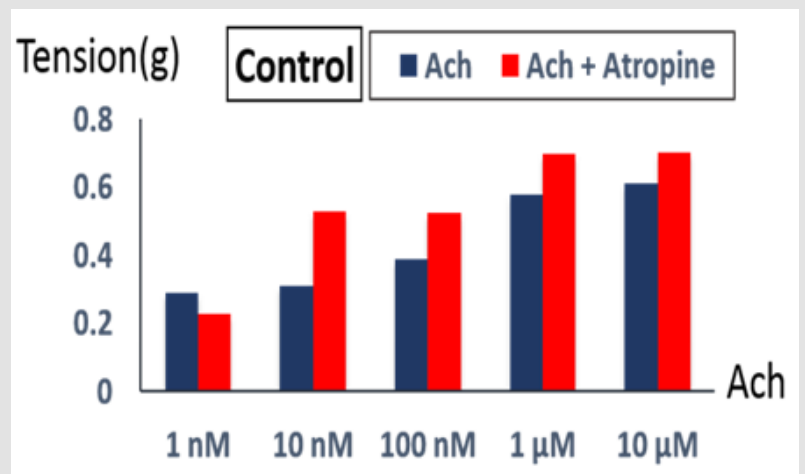

Figure 7: Control group response to different acetylcholine concentrations \pm atropine. Increasing acetylcholine doses results in increase ileal contractility before adding atropine, after adding atropine, no declining in ileal contractility was observed.

\section{Discussion}

The current study showed significant loss in body weight in DSS-treated mice compared to control ones. This finding agrees with other previous study which stated that 20 to $30 \%$ body weight loss is a sign of colitis in mice models [2]. Generally, loss in body weight is attributed to diarrhea and loss of appetite (Marchione, 2016). However, the current study found lower percentage of body weight loss compared to previous findings which was (20-30\%), despite using the same animal model. This difference may be attributed to employed DSS concentration and duration of colitis induction and age of the mice used in the experiment. In addition, increased permeability of the tight junctions is thought to contribute 
to UC and disruption in absorption of food which leads to weight loss. Also, previous studies showed that DSS has an anticoagulant property which may aggravate intestinal bleeding and cause loss of blood that is needed for nutrients absorption, consequently leading to weight loss. It had been found also that control mice have normal soft stool and negative results of fecal blood occult test. In contrast, DSS-treated mice have diarrhea with mild to moderate blood in stool by fecal blood occult test. All the above findings can be explained by the inflammatory response induced by DSS in the diseased mice.

This experimental study showed also that there were no significant differences in frequency in control and disease mice whereas amplitude was higher slightly in DSS-treated mice, which agrees with previous study which stated that in single cells, muscarinic receptor activation evokes calcium release from stores which raises the internal free calcium concentration and causes opening of calcium-activated potassium channels. The rise in internal calcium suppresses the voltage-dependent inward calcium current. A third important effect is the opening of channels which cause depolarization of the membrane and so increase action potential discharge and contraction in the whole muscle. They can pass Ca but the amount entering the cell is not sufficient to raise the internal calcium concentration appreciably. $[3,4]$ That is why amplitude is higher in control compared to disease mice while the frequency of contraction of longitudinal muscles is unchanged (Shi and Sarna, 1999; Jadcherla, 2002).

However, other studies indicate that in carbachol-induced ileal smooth muscle contraction, only low-dose induced contraction involves M2 receptors (Unno et al. 2005) and that although M2 receptors are involved in sustained carbachol-induced contraction of longitudinal smooth muscle of the mouse ileum, they are not involved in transient contractions (Takeuchi et al., 2006). Another good suggestion that ulcerative colitis induced in mice does not affect the intestinal cells of cajal. Disruption of the ICC network in an inflamed intestine may cause a decrease in membrane potential of smooth muscle cells because studies suggest that the ICC network mediates hyperpolarization of smooth muscle cells (Cohen 1986; Lu et al., 1997).). Several studies indicate that immunological events in intestinal muscle during surgical manipulation closely correlate with abnormal intestinal motility [5-8]. The current study also observed that control and disease mice showed normal response to different ACh concentrations in the absence and presence of atropine and this ultimately because (as previous studies found) that acetylcholine elicited a sustained contraction and an increase in potassium efflux in longitudinal muscle isolated from the ileum, so increasing concentrations of acetylcholine will ultimately increase the contraction of muscle .Adding atropine which is a competitive, reversible antagonist of the muscarinic acetylcholine receptors resulting in decrease contractions of both disease and control group because of blockage of receptors by the atropine. However, disease mice showed high contractions as it shown above in Figure 8 despite the effect of atropine and this is possibly because various contractile factors, such as acetylcholine, 5-hydroxytryptamine (5-HT), substance P, motilin and prostaglandin F2 $\alpha$ (PGF2 $\alpha$ ), induce intestinal smooth muscle cell contraction [9-22].

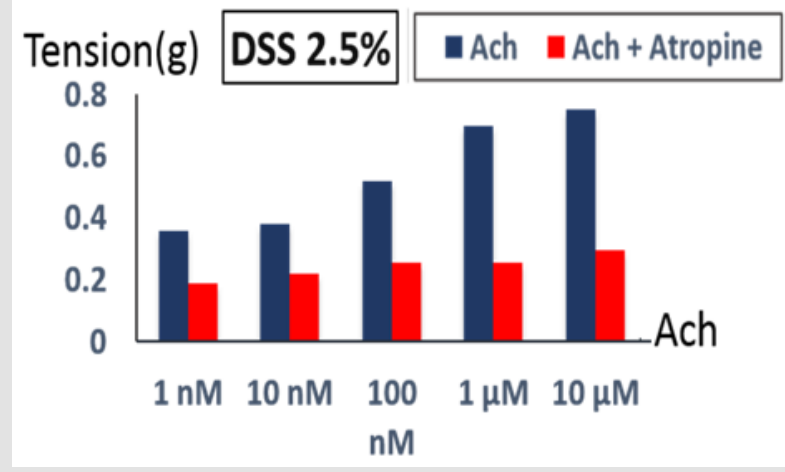

Figure 8: Disease group response to different acetylcholine concentrations tatropine. Increasing acetylcholine doses results in increase ileal contractility before adding atropine, after adding atropine, ileal contractility is declining.

\section{Conclusion}

This experiment aimed to study the effects of ulcerative colitis in ileal motility in a mice model which resembles ulcerative colitis in human beings because a better understanding of the pathophysiological grounds of altered ileal motility in ulcerative colitis may lead to a more in-depth knowledge of the accompanying symptoms and to better and more targeted therapeutic approaches. The overall findings suggest that ulcerative colitis has nothing to do with ileal motility, it does not affect the activity of ileum muscles. Ileal tissue shows normal response to different acetylcholine concentrations in the presence and absence of atropine. However, our findings lead to additional questions, how ulcerative colitis affects the gut mucosal permeability and studying the response to electrical field stimulation.

\section{Limitations}

a) Limited number of available mice in animal house.

b) Mice ileal tissue is very soft so easily can be damaged.

\section{Acknowledgement}

I would like to thank: My research supervisor (Dr. Ammar Boudaka), Research coauthors: Dr. Khalil Al Ajmi and Dr. Adil Ahmidat, My laboratory assistant (Ms. Intisar) and animal house staff. Dr. Hamza Babker, Course coordinator, Department of Biochemistry. Dr. Syed Rizifi, Statistical, Department of Family Medicine. This work was supported by Sultan Qaboos University, (physiology department). 


\section{References}

1. Damiani CR, Benetton, CA, Stoffel C, Bardini KC, Cardoso VH, et al. (2007) Oxidative stress and metabolism in animal model of colitis induced by dextran sulfate sodium. J. Gastroenterol. Hepatol 22(11): 1846-1851.

2. Chassaing Benoit, (2017) Dextran Sulfate Sodium (DSS)-Induced Colitis In Mice. Current Protocols in Immunology 104: 1-14.

3. Abraham C, Cho J (2009) Inflammatory Bowel Disease. New England Journal of Medicine 361(21): 2066-2078.

4. Danese S, Fiocchi C (2011) Ulcerative Colitis. New England Journal of Medicine 365(18): 1713-1725.

5. Egger B, Bajaj-Elliott M, MacDonald T, Inglin R, Eysselein V, et al. (2000) Characterisation of Acute Murine Dextran Sodium Sulphate Colitis: Cytokine Profile and Dose Dependency. Digestion 62(4): 240-248.

6. Fiocchi C (1998) Inflammatory bowel disease: Etiology and pathogenesis. Gastroenterology 115(1): 182-205.

7. Kappelman M, Porter C, Galanko J, Rifas-Shiman S, Ollendorf D, et al. (2011) Utilization of healthcare resources by U.S. children and adults with inflammatory bowel disease. Inflammatory Bowel Diseases 17(1): 62-68.

8. Lichtenstein G (2014) Medical therapy of ulcerative colitis. Springer.

9. Lichtenstein G, Scherl E (2010) Ulcerative colitis. Thorofare, NJ: SLACK Inc.

10. Parente J, Claudio S, V Campelo, Mirian P, LA Costa, et al. (2015) Inflammatory bowel disease in an underdeveloped region of Northeastern Brazil. World Journal of Gastroenterology 21(4): 11971206.

11. Strober W, Fuss I, Blumberg R (2002) The Immunology of Mucosal Models of Inflammation 1. Annual Review of Immunology 20(1): 495549.

12. Wagner A, Will O, Sturm C, Lipinski S, Rosenstiel P, et al. (2013) DSS induced acute colitis in C57BL/6 mice is mitigated by sulforaphane pretreatment. The Journal of Nutritional Biochemistry 24(12): 2085-2091.
13. (2017) Health Information, Resources, Tools \& News Online | Everyday Health. EverydayHealth.com. N.p.

14. Stengel PW, Yamada M, Wess J, Cohen ML (2002) M3-receptor knockout mice: muscarinic receptor function in atria, stomach fundus, urinary bladder, and trachea. Am. J. Physiol. 282(5): R1443-R1449.

15. Wegener JW, Schulla V, Koller A, Klugbauer N, Feil R, et al. (2006) Control of intestinal motility by the $\mathrm{Ca}(\mathrm{v}) 1.2$ L-type calcium channel in mice. Faseb. J 20(8): 1260-1262.

16. Won KJ, Suzuki T, Hori M, Ozaki H (2006) Motility disorder in experimentally obstructed intestine: relationship between muscularis inflammation and disruption of the ICC network. Neurogastroenterol. Motil 18(1): 53-61.

17. Camacho-Barquero L, Villegas I, Sanchez-Calvo JM, Talero E, SanchezFidalgo S, et al. (2007) Curcumin, a Curcuma longa constituent, acts on MAPK p38 pathway modulating COX-2 and iNOS expression in chronic experimental colitis. Int. Immunopharmacol 7(3): 333-342.

18. Van Crombruggen K, Van Nassauw L, Demetter P, Cuvelier C, Timmermans JP, et al. (2008) Influence of soluble guanylate cyclase inhibition on inflammation and motility disturbances in DSS-induced colitis. Eur. Pharmacol 579(1-3): 337-349.

19. Venkataranganna MV, Rafiq M, Gopumadhavan S, Peer G, Babu UV (2007) Mitra SKNCB-02 (standardized curcumin preparation) protects dinitrochlorobenzene- induced colitis through down-regulation of NFkappa-B and iNOS. World J. Gastroenterol 13(7): 1103-1107.

20. Villegas I, Alarcon de la Lastra C, Orjales A, La Casa CA (2003) New flavonoid derivative, dosmalfate, attenuates the development of dextransulphate sodium-induced colitis in mice. Int. Immunopharmacol 3(13-14): 1731-1741

21. Winterbourn CC, Brennan SO (1997) Characterization of the oxidation products of the reaction between reduced glutathione and hypochlorous acid. Biochem. J 326(1): 87-92.

22. Wolters G, Kuijpers LP, Kacaki J, Schuurs AH (1977) Enzyme-linked immunosorbent assay for hepatitis B surface antigen. J. Infect. Dis 136: 311-317.
ISSN: 2574-1241

DOI: 10.26717/BJSTR.2021.32.005327

Suaad Al Mandhari. Biomed J Sci \& Tech Res

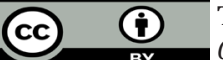

This work is licensed under Creative Commons Attribution 4.0 License

Submission Link: https://biomedres.us/submit-manuscript.php

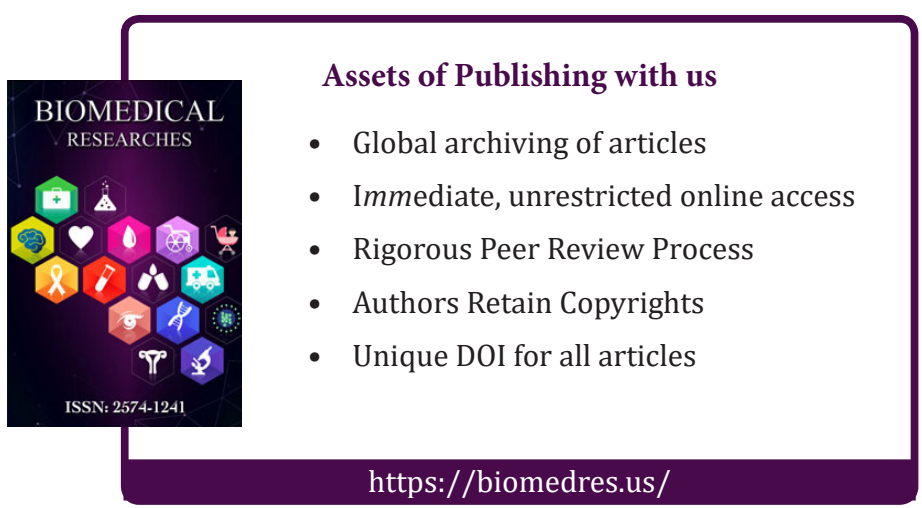

